\title{
Sujeto, intertextualidad, dialogismo y autoficción en la trilogía metaliteraria de Enrique Vila-Matas
}

\author{
Subject, intertextuality, dialogism and auto-fiction \\ in the metaliterary trilogy of Enrique Vila-Matas
}

\author{
Olalla Castro Hernández \\ Investigadora independiente \\ olalla castroh@yahoo.es
}

ORCID iD: https://orcid.org/0000-0002-6306-0639

\section{RESUMEN}

Este artículo indaga en tres de los elementos más recurrentes en la trilogía metaliteraria de Enrique Vila-Matas (conformada por la novelas Bartleby y compañía, El mal de Montano y Doctor Pasavento): la intertextualidad, el dialogismo y la autoficción. Estos mecanismos textuales, junto con otros (hibridación genérica, escritura fragmentaria) contribuyen a la problematización del concepto de Sujeto y a la creación de esa noción de identidad múltiple y abierta que domina los tres textos, construyendo un yo fragmentado y camaleónico.

Palabras Clave: intertextualidad; dialogismo; autoficción; sujeto; Vila-Matas.

\begin{abstract}
This article looks at the three most often recurring elements in the metaliterary trilogy of Enrique Vila-Matas (shaped by the novels Bartleby y compañia, El Mal de Montano and Doctor Pasavento): intertextuality, dialogism and auto-fiction. These textual mechanisms, together with others (generic hybridization, writing fragments) open up problems in the concept of Subject, and in the creation of this notion of multiple and open identities which dominate the three texts, creating a fragmented and chameleon-like I.
\end{abstract}

Key words: Intertextuality; Dialogism; Auto-fiction; Subject; Vila-Matas.

\section{INTRODUCCIÓN}

Ni el yo ni el mundo pueden ser pensados en el horizonte de sentido contemporáneo de manera sustancialista, totalizadora, universal, ahistórica, tal y como el racionalismo moderno pretendió hacerlo. El sujeto está hoy recorrido 
por completo por la alteridad, se siente múltiple y fragmentario e intuye que siempre será un desconocido para sí. De ahí el «yo es otro» de Rimbaud o el reconocimiento pessoano de un yo poliédrico, camaleónico («yo soy muchos»), habitado en lo profundo por la alteridad.

Este artículo parte de la consideración de que todos los elementos estilísticos y formales de la trilogía metaliteraria de Enrique Vila-Matas, formada por Bartleby y compañia, El mal de Montano y Doctor Pasavento (tres novelas que el propio autor reconoce como un conjunto narrativo que recorre la historia del Sujeto desde su nacimiento a su disolución) están puestos al servicio de la disolución del Sujeto moderno: de la construcción de un concepto de identidad abierto, dialógico, múltiple, en constante proceso de transformación, afín al tejido mismo de la vida. Los mecanismos textuales, las técnicas narrativas, la disposición del material verbal con el que se construye el texto, como advirtió Bajtín, están siempre orientados hacia el contenido. En el caso de la trilogía metaliteraria de Enrique Vila-Matas, dominada por completo por ese afán, tan propio del autor catalán, de cuestionar el concepto de identidad, todos los recursos desplegados en los tres textos (escritura fragmentaria, hibridación genérica, intertextualidad, dialogismo, autoficción) tienen por objeto la redefinición de la noción moderna de Sujeto, la generación de un yo en constante proceso de transformación que se niega rotundamente a ser Uno y que busca, de forma casi obsesiva y patológica, convertirse en Otros, ser muchos, huir de la prisión del nombre propio.

La hoja de ruta que seguiremos arranca con un análisis de la intertextualidad en la trilogía metaliteraria, con el que sacaremos a la luz cómo esta se utiliza para socavar el concepto de autor moderno, cómo las voces ajenas convocadas en la trilogía inscriben el texto en la tradición de la Modernidad negativa y cómo Vila-Matas ha convertido el reensamblaje de citas (lo que él llama el «parasitismo literario») en su personal programa estético. Indagaremos después en el carácter profundamente dialógico de la trilogía metaliteraria (donde veremos cómo los narradores-protagonistas de las tres novelas rehacen una y otra vez su discurso y su yo en una anticipación constante a la palabra $y$ el juicio ajenos) y, finalmente, reflexionaremos sobre el concepto de autoficción y su relación con el género del diario íntimo, centrándonos especialmente en El mal de Montano (que, de las tres novelas, es la que convierte en su leitmotiv la reflexión sobre la representación del yo en el diario íntimo).

\section{LA INTERTEXTUALIDAD EN LA TRILOGÍA METALITERARIA VILAMATIANA COMO DECONSTRUCCIÓN DE LA NOCIÓN MODERNA DE AUTOR}

Tal y como afirma el profesor Vázquez Medel (2005: 17): «Todo texto [...] se constituye en una retícula de encrucijadas, y es captado y significa, no por su inmanencia, sino precisamente por todo aquello que le transciende». Comen- 
zar a hablar de intertextualidad con esta anotación, supone aceptar que tal noción, en realidad, alcanzaría a todos los textos producidos desde todos los ámbitos discursivos. Todo texto es intertexto de muchos otros, ya que todo proceso de escritura se sirve de un lenguaje entrecruzado desde siempre por la alteridad. El sujeto es un Yo en el Otro, con el Otro que lo atraviesa y configura por entero. La alteridad está inscrita en el lenguaje mismo, en los lenguajes todos:

Las palabras significan aquello que la sociedad que las "produce" les asigna. Su funcionalidad y resemantización depende de los discursos socioculturales o literarios donde se inscriben. Por ello, no se puede hablar de una "pureza de sentido" que las abrigue. La palabra pertenece tanto a quien la enuncia como a quien se destina y la confronta; esto ya entraña la "palabra ajena" y su estatuto dentro del texto o discurso (Hernández 2011: 19).

La palabra posee una naturaleza dialógica, tal y como señaló Bajtín. Reconocer que todo enunciado es dialógico, significa reconocer que todo yo contiene al Otro y necesita al Otro para ser $^{1}$. El sujeto no conoce el verdadero soliloquio: nunca estamos solos cuando estamos a solas. Julia Kristeva, en su famoso artículo «Bajtín, la palabra, el diálogo y la novela» (en el que acuñó el término intertextualidad), indagando en la noción de dialogismo del teórico ruso, afirmó ya que «todo texto se construye como mosaico de citas, todo texto es absorción y transformación de otro texto» (Kristeva 1978: 190).

Esto no señala únicamente a la evidencia de que en todo texto pueden rastrearse «fuentes e influencias», como venía haciendo la teoría literaria positivista, sino a un hecho más profundo y estructural del propio lenguaje: la intertextualidad como elemento configurador de cualquier texto apunta a un hecho más amplio, la naturaleza dialógica de todo enunciado. Todo texto participa de un lenguaje social y se inscribe en una determinada cultura en un momento histórico concreto ( $\mathrm{y}$, al hacerlo, produce y reproduce, en términos althusserianos, un determinado inconsciente ideológico y libidinal), es fruto de la acumulación de los textos que configuran esa cultura y que resuenan en él como un eco. No se trata de rastrear la huella de determinados textos en otros, sino de asumir que esa huella es inasible, que no se puede rastrear, porque incluye potencialmente a toda la producción textual que precede a un texto y a todas las producciones textuales que lo rodean, y las más de las veces se produce de forma inconsciente y automática, se trata de un eco que ni el propio autor identifica: «Todo texto es un intertexto; otros textos están presentes en

${ }^{1}$ Hernández (2011: 30) señala, también, el carácter fronterizo de la palabra: «Puede decirse que, siguiendo los planteamientos vertidos en esta investigación, la palabra es frontera entre lo propio y lo ajeno y, antes de su apropiación, está anegada de intenciones externas, se encuentra en una posición interindividual y sólo adquiere un acento cuando es apropiada por el hablante o en un texto». 
él, en estratos variables, bajo formas más o menos reconocibles; los textos de la cultura anterior y los de la cultura que los rodean; todo texto es un tejido nuevo de citas anteriores» (Barthes 1986: 218).

La intertextualidad, por tanto, desmonta el propio concepto moderno de autor. El reconocimiento de la presencia en la obra de un escritor, consciente e inconsciente, de toda la tradición literaria que le precede y le rodea, implica una revisión de las nociones de la Estética moderna de genio, de autor, de originalidad y, a la postre, una revisión del concepto mismo de Sujeto. No nos interesa, por tanto, realizar un estudio en la línea de las investigaciones taxonómicas de «fuentes e influencias», sino observar hasta qué punto la intertextualidad en la trilogía metaliteraria vilamatiana revela una firme voluntad de deconstruir el propio concepto de autor y, sobre todo, de acabar con la idea de la identidad fija del yo, a través de esa multiplicación de la presencia de textos ajenos en la escritura propia.

Creemos, pues, que la conciencia de que todo texto está recorrido por entero por otros textos se plasma en la trilogía con el objeto de cuestionar el concepto mismo de Sujeto, en pos de una identidad coral, de la construcción de un yo habitado por los otros que puede convertirse, gracias a ello, en un ser múltiple y salvarse del hastío de ser siempre «idéntico» a sí mismo. El reconocimiento del eco de las voces ajenas en la voz propia es una manera más eficaz de combatir esa identidad fija, rígida y cerrada que la Modernidad normativa $^{2}$ pretendió adjudicarnos y que para Vila-Matas se convierte en una cárcel (la cárcel del nombre propio). La intertextualidad en la trilogía forma parte de esa búsqueda desesperada de Vila-Matas de nuevas «formas arquitectónicas» para la novela que desmonten la fábula de la identidad única:

La fatiga del desengaño del mundo le lleva a la activación máxima de la búsqueda de nuevas arquitecturas formales a la hora de estructurar su discurso narrativo; sus herramientas de investigación, esencialmente lúdicas y asociativas convierten su magnífica obra en un collage fluido que avanza engarzándose mediante un ars

${ }^{2}$ Este artículo concibe una Modernidad normativa (la que pretendía imponer con su razón prometeica y totalizadora el proyecto burgués, androcéntrico y etnocéntrico de Occidente que ya denunciaron en su momento los «maestros de la sospecha» y la Escuela de Frankfurt) y una Modernidad negativa (donde se situarían todos los contradiscursos críticos de los que bebe la narrativa vilamatiana), del mismo modo que distingue entre una Posmodernidad triunfal o de celebración (la Posmodernidad de los «juegos de lenguaje», de la hiperrealidad de la imagen, de la jouissance; la que vocea la muerte del Sujeto, la que celebra el fin de la historia, de las ideologías, y nos propone el relativismo ético y epistemológico como único horizonte de sentido posible) y una Posmodernidad de resistencia (la que se esbozó en los años setenta y que apelaba a lo heterodoxo, a lo fragmentario, a la multiplicidad, a la différence, con el objetivo de visibilizar a los invisibles de ese proyecto moderno occidental y armarlos como sujetos políticos). Asimismo, nuestra reflexión reivindica el vínculo de la narrativa vilamatiana con esa Modernidad negativa y rechaza su adscripción a una Posmodernidad triunfal, en la que ciertos críticos tratan de encasillarla. 
combinatoria que funde el tiempo del narrador con el de otros autores y obras de la literatura universal, hasta lograr esa identidad coral, poliédrica, cuestionándose a sí misma desde la ironía y la paradoja (Otxoa 2007: 31).

Los narradores-productores de los tres textos que nos ocupan, no solo reconocen el hecho indiscutible de que cada texto está recorrido por el eco de otros textos y, por tanto, el hecho de que en la voz «propia» de cada autor resuena el eco de muchas otras voces, sino que ponen todo su empeño en hacer explícito ese reconocimiento, en forma de alusión, de comentario, de paráfrasis o de cita directa a otras lecturas y autores, y tratan de dejar claro cuáles, de entre todas las voces posibles de la cultura que les precede, suenan con más fuerza en su interior. Esa forma de inscribir en el propio discurso los textos que sabemos que están sonando como música de fondo mientras escribimos, es, primero, un gesto de honestidad (si en todo texto resuenan otros textos, ¿no es más honesto hacer explícitas esas conexiones - hacerlo, al menos, con aquellas de las que el autor tiene conciencia - que ocultarlas, que pretender hacer pasar la escritura por reducto inalienable del yo, por producto de una individualidad única y separada de los otros, tal y como intentaba hacerlo el concepto moderno de autor?) y, segundo, una manera de reivindicar una determinada tradición literaria, manteniendo una actitud crítica hacia otras, que se invisibilizan al no incluirse en el enunciado mismo o se incluyen para polemizar con ellas abiertamente. Inscribirse en una determinada tradición literaria a través del mecanismo intertextual que pone en relación nuestro texto, no con todos los textos de nuestra cultura que nos preceden, sino con unos pocos, muy concretos - suponemos que Vila-Matas ha leído a muchos otros autores que, de alguna forma, también están presentes en su escritura y, sin embargo, no salen a la luz en su textos- indica un esfuerzo claro por recrear un determinado imaginario: adherirse a una línea determinada de escritura significa asumir también el fondo filosófico e ideológico que subyacía a esa tradición.

UN EJÉRCITO DE Disidentes: SIGUIENDO LA ESTELA DE LA MODERNIDAD NEGATIVA

Las voces que Marcelo, Girondo y Pasavento convocan en sus escritos y que constituyen el entramado de relaciones intertextuales de la trilogía, son todas ellas voces que ya disintieron de las nociones de Sujeto, Razón, Verdad, Progreso (todas ellas entendidas en términos absolutos), desde el interior de la Modernidad en la que se inscribían sus textos. Esas voces, que coinciden en los tres libros y se repiten constantemente en el resto de obras de Vila-Matas (las de Musil, Kafka, Joyce, Duras, Beckett, Perec, etc.), refuerzan con sus reflexiones y sus posiciones resistentes con respecto al inconsciente ideológico dominante y al canon literario instituido en sus respectivos emplazamientos, 
cronotopos, la postura disidente del propio Vila-Matas con respecto al sistema cultural y literario del que forma parte su obra. El escritor catalán convoca a un ejército de disidentes en la trilogía y, al hacerlo, pasa él mismo a engrosar sus filas, a reconocer su parentesco con toda una tradición crítica, la de la Modernidad negativa, en la que claramente se inscribe su obra.

Estamos de acuerdo con la anotación de Ródenas de Moya (2007: 290): «Se trata de una fórmula mestiza que convoca en una simultaneidad poligenérica y polifónica todas las voces de la gran literatura del pasado, que se incrusta en forma de citas, referencias indirectas o glosas hasta construir un concierto de ecos múltiples». Sin embargo, creemos que es necesario puntualizar que no son «todas las voces de la gran literatura del pasado» las que reúne Vila-Matas en sus novelas, sino a un determinado y heterodoxo grupo de escritores cuyo nexo en común es haberse constituido en voces críticas, disidentes con la Modernidad normativa (todos forman parte de la tradición de la literatura de la negatividad y las vanguardias). Los textos vilamatianos convocan precisamente a escritores pertenecientes a esa tradición resistente que hemos llamado Modernidad negativa, lo que refuerza nuestra hipótesis de partida de que todos los elementos puestos en juego en la trilogía vilamatiana no están funcionando a la manera en que lo hacen en la Posmodernidad triunfal, sino que enraízan precisamente con una tradición moderna que da cuenta (desde la periferia del sistema moderno, pero no fuera de él) de las fisuras de esa Modernidad normativa cuya apariencia fuerte y sólida comienza a resquebrajarse en todos los ámbitos:

No considero que el carácter visiblemente meta-literario de su factura [...] se explique mejor desde una supuesta posmodernidad que desde la crisis moderna del fin de siècle que alumbró la gran literatura y pensamiento posnietzscheano, donde a la desconfianza respecto del lenguaje (Holfmannsthal, Von Kleist), se une la quiebra del héroe como entidad sólida (Musil, Walser), la idea de una red infinita de textos que suplanta a la identidad personal (Borges, Pessoa) y la relevancia de la textualidad como horizonte de mundo (Blanchot, Barthes, Derrida). En esta línea hay que situar la fuente donde encuentra acomodo el laberinto literario sin salida por el que discurre la figuración del yo vilamatasiano (Pozuelo Yvancos 2012: 265).

Girondo se convertirá en el adalid de un tipo de literatura casi extinta, una literatura de riesgo, ajena al mercadeo y los porcentajes de ventas; una literatura en vías de extinción en la Posmodernidad complaciente con el neoliberalismo. Desde su trinchera, convocará al frente de resistencia a una serie de autores, en su mayoría pertenecientes a otro tiempo (al tiempo en que la Modernidad, aun siendo cuestionada en muchos de sus presupuestos, conservaba aún cierta fe en la belleza, en la verdad, en el sentido), que se definirá como más digno y auténtico, en el que la literatura no se había convertido aún en un negocio mundial, en una industria para masas, pero también a un puñado de 
autores contemporáneos que mantienen vivo hoy el espíritu de las vanguardias modernas, con la esperanza de ganar la batalla a los enemigos de lo literario. En ese ejército de insurrectos que enfrentan al batallón de topos dispuestos a acabar con la literatura, vuelven a aparecer muchos de los nombres que habían desfilado por Bartleby y compañía, e ingresan nuevos soldados: Justo Navarro, Julio Arward, Sergio Pitol, Perec, Kafka, Sebald, Walser, Walter Benjamin, Macedonio Fernández, André Gide, Beckett, Pessoa, Borges, Gombrowicz, Valéry, Renard, Michaux, Pavese, Blanchot.

Marcelo, Girondo y Pasavento son muy conscientes de que, a estas alturas de la jugada, después precisamente de las aportaciones de todos esos pensadores y escritores que desde la segunda mitad del siglo XIX venían cuestionado el estatuto de la Novela concebida como totalidad, las nociones de originalidad y autoría, el concepto de Sujeto y de Razón modernos, no es posible actuar como si nada, como si esas críticas no hubieran tenido lugar, como si no hubiesen provocado una profunda crisis en el imaginario moderno. Para generar una escritura con sentido en nuestro tiempo hay que dar cuenta de todo el sinsentido que ya supieron vislumbrar las vanguardias y los contra-movimientos literarios y filosóficos de la Modernidad y continuar con esa línea de ruptura con la lógica moderna que proponían sus escrituras. La obra no puede ser ya más que fragmentaria y estar compuesta por retazos de otras obras: «Decía Walter Benjamin que en nuestro tiempo la única obra realmente dotada de sentido - de sentido crítico también - debería ser un collage de citas, fragmentos, ecos de otras obras» (Vila-Matas 2007: 124).

\section{EL «PARASITISMO LITERARIO» COMO PROGRAMA ESTÉTICO}

Marcelo, Girondo y Pasavento son sujetos que despliegan un juego de ocultación/desvelación de sus respectivos yoes, que buscan perderse, diluirse en el eco de todas las voces que conjuran, pretendiendo con ello, paradójicamente, salir fortalecidos, reafirmar sus identidades personales, propias, concebidas estas ya como multiformes y en constante transformación, como particulares maneras de dar cabida a la alteridad dentro de sí mismos. Los tres saben que la originalidad en la escritura solo puede entenderse como ensamblaje de voces ajenas, como collage de citas que, a la luz de su nueva reinserción y contextualización, alcancen nuevos sentidos. La voz propia, singular, que persiguen y consiguen los tres narradores (que persigue y consigue, en última instancia, Vila-Matas), no solo reconoce la falacia de la construcción moderna del Sujeto único, centrado, cerrado sobre sí mismo, idéntico a sí, con unos límites claros que lo separan de los Otros, sino que está segura de que su única posibilidad de conseguir diferenciarse de los demás pasa por hacer explícito ese reconocimiento de la alteridad hasta convertir el texto en un diálogo polifónico con infinidad de textos y autores. El concepto de genio no está puesto 
al servicio ya de la originalidad, porque ni el genio ni la originalidad se entienden más a la manera kantiana, como las posibilidades de generar belleza de una individualidad única que posee un don innato otorgado por la Naturaleza. El genio no es ya aquel que no imita a nadie, sino aquel capaz de absorber la materia artística que le precede y convertirla en algo nuevo:

Como dice Gracq, el genio no es más que una aportación de bacterias particulares, una delicada química individual en medio de la cual un espíritu nuevo absorbe, transforma y, finalmente, restituye, con una forma inédita, no el mundo en bruto, sino más bien la enorme materia literaria que le precede (Vila-Matas 2010: 31).

Es precisamente el yo que reconoce formar parte ya de una trama lingüística, pertenecer a un horizonte de sentido conformado por un continuum textual y discursivo del que forma parte, el que puede atender a las voces que lo entrecruzan, abrirse a la alteridad, reconocerse en el dialogismo y encontrar en la manera de «reciclar» la palabra ajena, resemantizándola, una voz única como escritor y una identidad propia. El yo que asume la crisis de las esencias y la metafísica, el desvelamiento de que todo es lenguaje para el ser, de que no hay realidad objetivable, porque toda realidad es discursiva, histórico-social y, por tanto, el punto de vista propio está cercado por la mirada de los otros, acepta que la única literatura posible es ya la que relee y se reapropia de ese lenguaje que lo estructura y que lo posee.

Los narradores vilamatianos son sujetos que desean diferirse y diferir (aplazar la conclusión, el cierre de sus identidades, y diferenciarse así del resto de personas y de sí mismos), que, para dejar de ser quienes «son» y poder ser otros, para cambiarse a sí mismos, para transformarse, se autoperciben como sujetos múltiples, fragmentados. En el caso de Vila-Matas y sus narradores, convertirse en parásitos, en vampiros de otros escritores, es una manera más de reconocerse múltiples y de zafarse de sus propias identidades, concebidas como una carga, como un lastre. La apropiación de la palabra ajena, la intertextualidad, se configura en los tres textos como forma de negación de la identidad cerrada moderna, pero, sobre todo, se utiliza paradójicamente para hacerse con una voz personal, distinta, propia, porque solo en los otros el yo puede encontrar «lo propio»:

Poco a poco el porcentaje de lo copiado en mis poemas fue decreciendo y así lentamente, pero con cierta seguridad, fue apareciendo mi estilo propio, siempre construido, poco o mucho con la colaboración de los escritores a los que les extraía la sangre para beneficio propio gracias al vampirismo y a la colaboración involuntaria de los demás, de aquellos escritores de los que me valía para encontrar mi literatura personal. [...] Y encontré lo mío en los otros, llegando después de ellos, acompañándoles primero y emancipándome después (Vila-Matas 2007: 122). 
Así, en la trilogía, la intertextualidad, el parasitismo literario, se convierten en programa estético. Vila-Matas transforma lo que algunos ven como una tara en su literatura, la constante presencia de otros escritores, el que sus novelas se construyan como un collage de citas, como un tejido de intertextos, en lo más personal y propio de su escritura: «Vi que no tenía por qué preocuparme de mi historia de parásito, sino convertirla en un programa artístico propio, convertirme en un parásito literario de mí mismo, sacar partido de la reducida pero autónoma parte de mi angustia y de mi obra que podía considerar mía» (Vila-Matas 2007: 124).

Sin embargo, la autoparodia y la ironía alejan los textos de Vila-Matas del simple pastiche posmoderno. La reflexión sobre el propio texto inserta en el interior del enunciado supone la introducción de la figura del lector, es decir, del Otro, en el texto:

Vila-Matas, ese okupa, ese vampiro literario, ha convertido el inquietante "síndrome de Rendfield" en un elemento constitutivo de su poética. Es decir, la convocatoria a otras voces y otros ámbitos en su espacio literario no estaría trabajada simplemente en el plano del pastiche, pues la autoparodia y las reflexiones de sus propios libros, al interior de ellos mismos, estarían proporcionando un componente alternativo a la categorización de su literatura como simplemente posmoderna (Ríos Baeza 2012: 91).

Vila-Matas decide que esa labor de sacar a la luz las voces ajenas que resuenan en su interior y que conforman su escritura, que ese empeño de construir sus propios textos a partir de la materia literaria que le precede, sea precisamente aquello que lo distinga del resto, que lo dote de una voz propia dentro de la literatura. Su propósito es, pues, forzar la intertextualidad, hacerla omnipresente, llevarla hasta el límite, convertirla en programa estético, para hacer con ello algo «nuevo», diferente, único:

Yo, en cambio, siento el orgullo del vampiro. Por ejemplo, durante años, actué en literatura como un perfecto parásito. Posteriormente me fui liberando de mi atracción por la sangre de las obras ajenas, y hasta, con la colaboración de éstas, me fui haciendo con una obra inconfundiblemente mía: discreta, de culto, medio oculta, tal vez excéntrica, pero que me pertenece y está muy alejada ya del uniformado ejército moderno de lo idéntico (Vila-Matas 2007: 220).

La presencia de los otros en el texto propio, la deliberada apuesta por la intertextualidad como «forma arquitectónica», como materia de construcción del entramado textual, es el camino que encuentra Vila-Matas para hallar una «brizna de literatura propia». Se trata de aceptar que se escribe siempre «después de otros»y de llevar a esos «otros» al interior del texto propio para, junto a ellos, con su ayuda, definir una escritura personal, distinta, pero también se trata de asumir, y esto es lo más importante, que la conciencia de que la vida ya no reside en la totalidad y no puede ser concebida más como unidad impli- 
ca también que el Sujeto desaparece tal y como lo entendió la Modernidad (ya que el Sujeto moderno estaba hecho «a imagen y semejanza» de ese deseo de totalidad, de unidad, de orden que la Modernidad proyectó en el Universo, en la vida). El yo ha de renunciar a una identidad única, cerrada, ha de renunciar a la falacia moderna del "conócete a ti mismo, hazte a ti mismo» (ha de renunciar, por tanto, a concebirse a sí mismo como Sujeto, como dueño y señor de sí), pero esa conciencia de que no somos accesibles ni transparentes para nosotros mismos, de que nunca llegamos a conocernos, no se vive con angustia, sino con regocijo, porque es precisamente lo que nos permite convertirnos en otros, en muchos, hacernos con una identidad coral conformada por el conjunto de voces, de rostros, que nos pueblan:

No conocerse nunca o sólo un poco y ser un parásito de otros escritores para acabar teniendo una brizna de literatura propia. Se diría que éste fue mi programa de futuro desde que empezara a escribir copiando a Cernuda. Tal vez lo que he hecho es ir apoyándome en citas de otros para ir conociendo mi exiguo territorio propio de subalterno con algunos destellos vitales y al mismo tiempo descubrir que nunca llegaré a conocerme mucho a mí mismo — porque la vida ya no es una unidad con un centro, "la vida", como decía Nietzsche, "ya no reside en la totalidad, en un Todo orgánico y completo"-, pero en cambio podré ser muchas personas, una pavorosa conjunción de los más diversos destinos y un conjunto de ecos de las más variadas procedencias (Vila-Matas 2007: 122-123).

La identidad única del yo solipsista moderno es rebatida con ese concierto de voces ajenas donde el yo ejerce solo como director de orquesta y sabe que únicamente la manera en que decida hacer sonar ese conjunto de voces podrá hacerlo poseer esa «brizna de literatura propia» que con tanto ahínco busca.

La identidad se reconoce como coral, abierta, múltiple, porque estamos habitados por los otros en el momento mismo en que somos arrojados a un horizonte lingüístico que no nos pertenece, constituido por la alteridad. En la trilogía, el esfuerzo por convertir las relaciones intertextuales en programa estético, en «forma arquitectónica» por excelencia, se suma a otros mecanismos que sacan a la luz el carácter dialógico del enunciado literario.

\section{LA TRILOGÍA METALITERARIA VILAMATIANA: UNA CONSTANTE ANTICIPACIÓN A LA PALABRA AJENA}

Bartleby y compañía, El mal de Montano y Doctor Pasavento son novelas profundamente dialógicas, donde, además del dialogismo externo (el debate que se genera dentro de los textos por parte de Vila-Matas con la literatura, la cultura y el inconsciente ideológico dominante en nuestro tiempo), observamos un fuerte dialogismo interno y una constante anticipación a la palabra ajena. Un ejemplo de cómo el dialogismo se lleva al extremo de la autoparodia lo 
vemos en Bartleby y compañía cuando Marcelo, al no obtener respuesta a la carta que escribe a Derain, decide contestarse a sí mismo, escribirse una carta firmada por Derain (que nosotros, como lectores, creeremos hasta mucho más tarde que, efectivamente, ha escrito Derain: no será hasta que Marcelo reciba una auténtica carta de Derain cuando sepamos que la primera era una «falsa» carta escrita por el propio Marcelo). También son significativos los diálogos ficticios que Marcelo imagina tener con Salinger en la escena del autobús, los diálogos que mantiene Girondo con Musil o las conversaciones de Pasavento con el viejo Ramón y su mujer en su viaje a la Patagonia (viaje que después sabremos que solo ha tenido lugar en la imaginación de un Pasavento que proseguía parapetado en la Rue Vaneau mientras fabulaba estar huido en el territorio más austral de América).

Pero la trilogía es profundamente dialógica mucho más allá de esos momentos explícitos y autoparódicos que recuerdan ligeramente al Hombre del subsuelo de Dostoievski (donde Bajtín vio el ejemplo más radical de palabra bivocal, de dialogismo interno), porque se construye toda ella como una permanente anticipación a la palabra ajena, en varios sentidos. La escritura vilamatiana busca concienzudamente a su lector y lo introduce en el propio texto, hasta el punto de que en muchos momentos es la anticipación a la reacción del lector, a la réplica lectora, la que hace virar la escritura hacia uno u otro lugar. El lector, ese Otro necesario, está siendo interpelado constantemente en esos guiños intertextuales y en el despliegue de los juegos entre la cita real y la falsa, la inventada, las menciones a escritores apócrifos, las paráfrasis de textos ajenos hechos pasar por propios y la apropiación de la palabra de otros, con la variación y el retoque de citas $\mathrm{y}$, por supuesto, en el propio mecanismo de ficcionalización de elementos biográficos del autor que se proyectan en sus personajes, incluso en el propio empeño vilamatiano en convertirse él mismo en yo figurado, «en personaje de sí mismo» (como reza uno de los títulos de las Figuraciones del yo en la narrativa de Pozuelo Yvancos). Vila-Matas está buscando y generando un «lector tipo» en su obra, un lector con el que establece un diálogo constante, con el que polemiza y al que rebate argumentos, con el que juega al despiste y con quien procura complicidades y anexiones. Y es la relación con ese lector la que configura el texto por entero. Las más de las veces, da la impresión de que ese «lector ideal» que se busca en el texto y con el que se juega y se ironiza bien pudiera ser un experto en literatura, un crítico literario.

Los narradores de la trilogía se adelantan constantemente a la palabra ajena, explicando lo escrito, revisando posiciones o reafirmándose en ellas, introduciendo el discurso crítico al que creen que sus textos está dando lugar y apresurándose a responder a cualquier interpretación desviada de su propia intención como autores. Hay un análisis constante de la propia escritura en el interior del texto, una explicación de por qué se escribe como se escribe, una defensa de las estrategias narrativas y la arquitectura formal que se escoge, que 
se incluye en el texto como clara anticipación a los posibles ataques de la crítica (hay una especie de miedo a ser malentendido y una necesidad casi patológica en los narradores de la trilogía de explicar y justificar cada elección tomada como escritores).

En la trilogía hay un diálogo con toda la tradición literaria que precede a Vila-Matas y con aquella que lo envuelve, que lo rodea. No solo existe un esfuerzo claro por inscribirse en una determinada tradición crítica, vanguardista, sino que hay un diálogo con la literatura contemporánea y con la crítica literaria actual, un diálogo que defiende las posturas propias y ataca constantemente las ajenas (y ese ataque es ya una maniobra defensiva que se anticipa a las posibles críticas, a la posibilidad de que su propuesta literaria no sea aceptada en el panorama cultural en que se inserta). Por tanto, esa estrategia de anticipación al intérprete, al lector, que los narradores de la trilogía llevan a cabo haciendo una transposición, convirtiéndose ellos mismos en sus propios lectores para prever antes que otros las posibles preguntas, dudas o críticas que puedan surgir ante el texto, es, por un lado, una muestra de dialogismo interno (ya que, como hemos visto, el texto se construye, progresa, avanza, anticipándose a la palabra ajena y tratando de contenerla, tanto en el sentido de llevarla dentro, de introducirla en su interior, como en el de reprimir o sujetar su movimiento, con el propósito de desactivarla o reconducirla antes incluso de que se produzca) y, por otro, una muestra de dialogismo externo (del propio diálogo que mantiene la obra con su entorno, con el resto de discursos sociales, con lo normativo y canónico en su tiempo/espacio, con el propio horizonte lingüístico al que pertenece).

Considerando el dialogismo interno, la palabra bivocal, como el modo en que el héroe vive su autoconciencia en oculto diálogo o polémica con el otro (polémica que gira en torno a la imagen que de él tienen los otros, la imagen que él tiene de sí mismo y la que quiere que tengan los otros), la trilogía vilamatiana es sin duda profundamente dialógica. Doctor Pasavento es un texto orientado hacia el deseo de reconocimiento del otro como condición indispensable para el propio reconocimiento del yo. Pasavento necesita que los otros verifiquen, acepten su nueva identidad para conseguir liberarlo así de su vieja identidad de escritor (sin ese reconocimiento del otro de su nueva identidad, Pasavento sabe que no podrá convertirse en ese doctor en psiquiatría que aspira a ser). Además, Pasavento estructura su relato y condiciona su acción, su huida, siempre en función del otro, de un otro al que rechaza y busca con la misma intensidad (su deseo de huir, de desaparecer, de no ser visto, es a la postre deseo de ser buscado, de que alguien perciba su ausencia, de ser echado en falta por los otros). Esto también sucede en El mal de Montano, cuando Girondo va desmintiendo lo narrado y con ello, desmintiendo la propia imagen que había dado de sí mismo al Otro, al lector. En Bartleby y compañía, además, todas las voces están contenidas en la voz de Marcelo. Aunque existe el contrapunto de unas cuantas voces ajenas (Derain y Juan, el supuesto amigo de 
Marcelo), esas otras voces llegan siempre a través de la narración del propio Marcelo, se inscriben en el texto que Marcelo escribe y están, por tanto, pasadas por el tamiz de la propia voz de Marcelo (eso sin contar con que, dada la naturaleza del enunciado, del texto de Marcelo, no podemos estar seguros de si esas voces son «reales» o fingidas, inventadas por él mismo).

Los diálogos con otros personajes en toda la trilogía, dado el carácter de ejercicio de escritura de los narradores-personajes que adquieren los tres textos, están siempre escritos, narrados, por los propios personajes-protagonistas. Y esos personajes, Marcelo, Girondo y Pasavento, narran con el mismo tono sus diálogos con otros personajes de las novelas que se suponen «reales», verdaderos, dentro del mundo posible (siguiendo la terminología de Eco) que se nos ofrece en los textos, y los que son imaginados, fabulados, o tienen lugar en mitad del sueño o del delirio de los narradores. Girondo nos cuenta la escena en la librería con su hijo Montano, que luego descubriremos que era una fabulación, una ficción, con la misma intensidad y los mismos signos de verosimilitud (dentro de situaciones dominadas por el absurdo y lo inverosímil a las que, según los términos en que se nos propone el pacto ficcional desde el comienzo del libro, damos crédito) con que nos narra otros hechos que damos por «reales». Las conversaciones entre Girondo y Tongoy resultan tan verosímiles como los diálogos que Girondo mantiene en sueños con Pessoa o Musil.

Pero lo que más nos interesa señalar en estos breves apuntes sobre el dialogismo en la trilogía es cómo los personajes mismos de las tres novelas se convierten en sujetos dialógicos, con todas las connotaciones éticas que el dialogismo implica. Y es que, como señala el profesor Domingo Sánchez-Mesa, el dialogismo bajtiniano es una «cultura de la responsabilidad» ${ }^{3}$. El reconocimiento del «yo» de su necesidad de los otros, de su dependencia absoluta de la alteridad, es un acto profundamente ético, alejado radicalmente del individualismo irresponsable y de la patológica indiferencia por el destino del otro que parece haberse impuesto en la Posmodernidad triunfal.

\section{EL YO COMO FICCIÓN: DIARIO ÍNTIMO Y AUTOFICCIÓN}

Aunque estemos tratando de desbrozarlos, todos los elementos «formales» o «arquitectónicos» que venimos analizando en este epígrafe están profundamente relacionados, imbricados, y trabajan en la misma dirección de apertura del enunciado, de desestabilización del sentido, de ruptura con los puntos de vista rígidos y monologizantes típicos de la Modernidad normativa. Así, en la trilogía no se entiende la autoficción sin la hibridación textual (el mestizaje

\footnotetext{
${ }^{3}$ No en vano su estudio sobre el dialogismo bajtiniano lleva por título Literatura $y$ cultura de la responsabilidad. El pensamiento dialógico de Mijaíl Bajtín (Sánchez-Mesa Martínez 1999).
} 
genérico), la intertextualidad, el dialogismo interno o la apuesta por las formas abiertas y fragmentarias. Lo que nos importa subrayar de la autoficción (o mejor, de la «figuración del yo») en la trilogía vilamatiana es que está puesta, en todo momento, junto con el resto de elementos analizados con los que se relaciona, al servicio de la cuestión central que nos ocupa: el desmontaje de esa imagen del yo como Cogito.

La mónada del Sujeto moderno es cuestionada constantemente a través de ese permanente juego entre lo real y lo ficticio, porque al diluirse los límites entre la literatura y la vida, se diluyen los propios límites entre el yo de Vila-Matas autor, como el sujeto «real» que escribe las tres novelas, y los yoes de sus personajes (como sujetos ficcionales que escriben, en el interior del mundo posible que cada uno de los libros propone, los textos que leemos), de modo que la identidad, tanto del autor como de sus personajes, se resuelve en un juego de máscaras (el autor se enmascara tras sus personajes, los utiliza para que el lector los confunda con él mismo, para generar en el lector la impresión de ser él mismo uno de sus personajes de ficción, pero, a la vez, él actúa como máscara de sus personajes, al prestarles ciertas vivencias propias, al conferirles fragmentos de su biografía). Se escribe sobre uno mismo, paradójicamente, con el deseo de ocultarse (bajo la máscara de la ficción). Vila-Matas autor, al transferir ciertos elementos autobiográficos a sus personajes, se desprende de parte de sí mismo, se aleja de sí, se percibe a sí mismo como otro, tal y como reza la cita de Justo Navarro en El mal de Montano: «Te agarras a lo que tienes más cerca: hablas de ti mismo. Y al escribir de ti mismo empiezas a verte como si fueras otro, te tratas como si fueras otro: te alejas de ti mismo conforme te acercas a ti mismo» (Vila-Matas 2007: 143).

En todo momento, lo autoficticio está actuando para desactivar el propio concepto de biografía, para diluir los límites entre realidad y ficción y entre el Yo y el Otro. Este doble juego de máscaras se sucede gracias al hecho de que los personajes-narradores de la trilogía sean, los tres, escritores (y no simplemente escritores en abstracto, sino los «autores», los productores efectivos de los textos que leemos que, además, no podemos olvidarlo, escriben sobre sí mismos, narran sus propias historias personales): «Podría decirse que la figuración principal del yo en Vila-Matas es la del escritor en el mecanismo de su búsqueda. Enrique Vila-Matas ha conseguido que el mapa de su recorrido sea patente al mismo tiempo que se va haciendo» (Pozuelo Yvancos 2010: 180).

Ese hecho resulta determinante para que puedan darse en la trilogía los particulares juegos autoficticios que se dan. Vila-Matas, autor «real», puede proyectar en sus personajes, escritores como él y autores de los textos de ficción que leemos, sus propias dudas, certezas, planteamientos estéticos, filias y fobias (esto es, elementos de su propia biografía), pero a la vez, al ser sus personajes los responsables del texto que leemos dentro del mundo posible que se nos propone, puede alejarse completamente de sus textos, ocultarse, desaparecer. Al ser, además, el enunciado mismo una «representación», una «figuración» 
del acto de escribir, pueden inscribirse en el texto las marcas de todo proceso creativo: las dudas, los deslizamientos, las reflexiones, los comentarios que surgen en los narradores-personajes conforme escriben y con respecto a lo que escriben, lo cual facilita el despliegue de la autoparodia y la ironía como mecanismos que funcionan constantemente en los tres textos.

En realidad, teniendo en cuenta las definiciones teóricas de la autoficción ${ }^{4}$ más aceptadas (sin ir más lejos, la del propio Doubrovsky), ninguna de las tres obras analizadas encajaría en realidad en tal categoría, ya que la identidad nominal del autor real y el narrador-personaje no coinciden (algo que sí ocurre en París no se acaba nunca y que nosotros percibimos como una diferencia lo suficientemente significativa como para separar esta obra de las otras tres). De ahí que hablar de figuraciones del yo, término propuesto por Pozuelo Yvancos, menos restringido y con implicaciones mucho más ricas, nos parezca más acertado. Esto supone afirmar que la cualidad principal del yo en las tres novelas que nos ocupan (incluso del propio yo que Vila-Matas se construye en artículos y entrevistas, como «personaje de sí mismo») es el hecho de configurarse como yo figurado (fantaseado, inventado, ficcionalizado, incluso fastasmático, tal y como explica Pozuelo). No se trata solo de que en Marcelo, Girondo y Pasavento podamos vislumbrar coincidencias biográficas con el propio Vila-Matas (y extraigamos, pues, parecidos razonables entre el autor y sus personajes), es que esos personajes, tratados como seres «autónomos», con entidad ficcional propia, separados como narradores-personajes y como escritores de quien, en el circuito extraliterario, actúa como autor, se configuran a sí mismos también como yoes figurados, en la medida en que construyen su personalidad con retazos de las personalidades de otros escritores, con fragmentos de sus lecturas predilectas, con ensoñaciones, fingimientos, invenciones, que ellos mismos reconocen más tarde como tales (o no, con lo que, como lectores, ponemos permanentemente bajo sospecha su credibilidad).

El «pacto ficcional» que sella el lector con estos yoes figurados es un pacto ambiguo, que está basado, no ya en la suspensión de la incredulidad, sino en la permanente sospecha, en la incredulidad con respecto a la «verdad»o «realidad» de lo que nos cuentan. Se trata de una especie de pacto ficcional

${ }^{4}$ Vicente Luis Mora propone el concepto de Autonovela, muy interesante, para aludir a Bartleby y compañia: «La Autonovela sería el punto de encuentro de la autoficción con la metaliteratura, donde los materiales autobiográficos y las reflexiones constructivas generan un tipo de libro que supone la escritura de uno (mismo), con un mayor o menor grado de ficción y teoría, según autores» (Mora 2012: 43). A lo que añade una nota esencial para nuestra reflexión: «La Autonovela no sería tanto un libro del yo, no tanto una muestra pura de literatura egódica, como un síntoma de la conciencia de la dislocación del yo, de su dispersión: si hay algo que montar es porque está fragmentado; si hay que construir una historia de uno es porque la unidad subjetiva es una ficción, una construcción narrativa de la identidad» (Mora 2012: 45). 
«doble»: hay un primer pacto ficcional, el que establecemos con Vila-Matas autor, que nos lleva efectivamente a suspender la incredulidad y aceptar el mundo posible que el texto nos propone, esto es, a asumir como autores del texto que leemos a los narradores-protagonistas del circuito interno de comunicación literaria, y un segundo pacto, el que establecemos ya desde dentro de ese mundo posible e imbuidos en la propia lógica de la ficción, con esos escritores-personajes que narran sus historias. Ese segundo pacto, que podríamos llamar pacto «interno», para funcionar, necesita que sospechemos constantemente de la voz narrativa, que arroja falsas pistas que nos llevan a interpretar como «reales», a dar por «verdaderos», una serie de acontecimientos y anécdotas que después se revelan en la propia narración como «engaños», figuraciones, inventos.

Lo más relevante de esta vuelta de tuerca que Vila-Matas y sus personajes hacen de la autoficción, tal y como subraya Pozuelo, es el hecho de otorgar exactamente la misma credibilidad, de tratar con el mismo grado de verosimilitud y el mismo estatuto de «verdad» a lo «real» y a lo fingido, inventado o soñado. Esto se observa tanto en Vila-Matas autor, que juega constantemente al despiste inventando apuntes biográficos imposibles e introduciendo anécdotas personales en sus novelas, fingiendo que estas forman parte de la ficción, que les ocurren a sus narradores-personajes, como en sus propios personajes, que narran con el mismo tono y otorgando el mismo estatuto de «realidad», de «verdad», lo que como lectores interpretamos que les sucede «en realidad» (en la «realidad» de la ficción, se entiende) y lo que les sucede en sueños, o lo que sencillamente fabulan o inventan que les sucede. Aquellas anécdotas vitales o episodios personales de los escritores-personajes de la trilogía que se revelan como figuraciones, como ficciones, sistemáticamente se nos narran bajo la misma fórmula: primero se nos presentan como algo que ha tenido efectivamente lugar en la «realidad» de la ficción que aceptamos como verosímil, y después, una vez que en el propio relato se produce un desmentido de esa «realidad», una vez que el propio personaje revela que nos «mintió», se tornan en algo inventado o fingido. Hay numerosos ejemplos de esto, desde el encuentro de Marcelo con Salinger, que se narra como encuentro «real» para más adelante confirmarse como fabulación, o la primera carta que nosotros como lectores creemos que ha enviado Derain a Marcelo y que algo más adelante se nos presenta como una «falsa» carta escrita por el propio Marcelo, a la supuesta biografía plasmada en la nouvelle-diario que Girondo escribe al comienzo de El mal de Montano, que en la segunda y la tercera parte del libro se nos advierte pura ficción, mentira, fabulación, para terminar con los viajes de Pasavento (algunos se llevan a cabo efectivamente, otros se revelan como fingidos, soñados, imaginados) o sus relaciones con los distintos personajes secundarios (algunos «existen», como Morante, otros sospechamos que no, como Humbol o los psiquiatras). 
Ese mecanismo que iguala la realidad y la ficción, lo vivido y lo imaginado o soñado, termina por convertirlo todo en literatura (y en eso, tanto Vila-Matas autor, decidido a convertir su propia vida en ficción, como sus escritores-personajes, empeñados en presentar bajo las mismas fórmulas discursivas lo real y lo ficticio, lo sucedido y lo inventado, hasta que ambos se confundan, coinciden plenamente):

\begin{abstract}
Vemos, por tanto, un tránsito constante a lo largo de la tetralogía entre elementos autobiográficos con su alternativa inventada, y un cambio tonal que va desde lo serio o lo elegíaco hasta lo humorístico. Vemos asimismo que tales rasgos y tonos comparten los narradores, se llamen Marcelo, Montano, Vila-Matas o Pasavento. La figuración lo ha transmutado todo, convertido en literatura (Pozuelo Yvancos 2010: 191).
\end{abstract}

La clave, repetimos, es que tanto Vila-Matas autor (en el circuito externo de comunicación literaria) como sus narradores-personajes (escritores también, autores también, en el circuito interno de comunicación literaria) dan la misma importancia y narran bajo los mismos principios de verosimilitud lo que ocurre y lo que se imaginan que ocurre, de modo que para el lector resulta imposible dilucidar cuándo está ante la narración de la «verdad» y cuándo ante un «engaño», lo cual activa un mecanismo de recelo, de duda, de sospecha, que funciona permanentemente y que determina el tipo de pacto ficcional «interno» que establecemos con la voz narrativa, pero que acaba también trasladándose al circuito externo y se convierte en sospecha del propio Vila-Matas, al que acabamos percibiendo, en la realidad extraliteraria, material, como un fingidor de sí mismo.

Al constituirse las voces narrativas como figuraciones de escritor, todo análisis se duplica en un juego de espejos, e incluso, como estamos viendo, se duplica el propio pacto ficcional. Como venimos diciendo, el pacto ficcional «interno» que sellamos con los narradores-personajes de la trilogía, por el cual suspendemos la incredulidad como lectores y aceptamos como «verdaderas», «plausibles», la lógica, las reglas del mundo posible que sus textos proponen, es transgredido constantemente por la propia voz narrativa. Esta ruptura o debilitamiento del pacto ficcional «interno» en realidad fortalece el pacto ficcional externo que establecemos con el autor, ya que confirma nuestra total aceptación de que nos hallamos frente a los respectivos relatos autobiográficos de Marcelo, Girondo y Pasavento, de ahí que como sus lectores nos sintamos «engañados» cuando estos nos confiesan habernos «mentido». Ese pacto ficcional «interno» que establecemos con esos escritores-narradores-personajes, a los que les exigimos la coherencia y la verosimilitud necesarias para poder suspender la incredulidad, se rompe constante y deliberadamente por parte de los personajes que, además, nos «mienten» para después confesarnos sus mentiras y explicarnos cómo y por qué han convenido en mentirnos: 
En Bartleby y compañia el punto principal de inflexión para una nueva forma de novela lo ofrece el juego con los límites genéricos y principalmente la transición constante que en este libro se da entre lo real y lo imaginario, lo inventado y lo sucedido. Los dos mecanismos para producir esa impresión son la mixtura de géneros que pone al mismo nivel el ensayo, el diario íntimo y la novela, y el mecanismo conocido como autoficción que provoca el constante juego con la credibilidad de la voz narrativa, sometida a sospecha (Pozuelo Yvancos 2007: 40).

No es casualidad que el género escogido en El mal de Montano (escogido para transgredirlo y mezclarlo con otros muchos, para convertirlo, pues, en algo distinto) sea el diario íntimo ${ }^{5}$, un género desde sus inicios híbrido, que tiene que ver con lo autobiográfico, pero que lo trasciende siempre, y donde caben todo tipo de géneros y subgéneros (lo poético, lo ensayístico, lo aforístico, lo narrativo...), que, como explica el propio Girondo, puede tomarse cualquier libertad, siempre y cuando respete el calendario (esto es, mientras se pliegue a la linealidad temporal progresiva):

Como ya observara Blanchot, el diario, tan dócil a los movimientos de la vida y capaz de todas las libertades - ya que sueños, ficciones, pensamientos, comentarios sobre uno mismo, acontecimientos importantes o insignificantes, todo al diario le va bien en el orden o el desorden que se quiera-, está sometido sin embargo a una cláusula de apariencia ligera pero tremenda: debe respetar el calendario (Vila-Matas 2007: 166-167).

El diario íntimo, que se convierte en manos de Vila-Matas en género híbrido, narrativo, ficcional, ensayístico, sirve para cuestionar al Sujeto unívoco de la Modernidad normativa y puede considerarse el hilo conductor de El mal de Montano. Durante toda la novela el diario íntimo está presente de distintas formas. No solo el texto es, a la postre, un diario (diario que se va convirtiendo en novela, en diccionario de autores, en conferencia...), el de Girondo, sino que en él van insertándose a cada paso (sobre todo en la segunda parte de la novela) los diarios de otros escritores y las propias reflexiones teórico-críticas sobre el género que elabora el protagonista. Como ya vimos cuando analizamos el mestizaje genérico en la trilogía, Vila-Matas vuelve a escoger un género para transgredirlo, transformarlo, mezclarlo con muchos otros y, a la postre, para cuestionar los principios y elementos mismos en los que se supone que se sustenta. Vila-Matas utiliza el diario íntimo, el género en prosa al que se le presupone, junto a la autobiografía, un acercamiento más profundo y sincero al yo que escribe, el género teóricamente más personal, el que está menos cerca de la ficción y más cerca de la «verdad» de su autor, de la «realidad»,

5 «¿Por qué el Diario? Precisamente porque es el género de la vida, el más personal, el que se presenta como no ficticio» (Pozuelo Yvancos 2010: 211). 
para desmontar, no solo todas esas presuposiciones, sino la idea misma de Sujeto, de identidad única y cerrada, de Verdad o de Realidad.

En lugar de ese Sujeto portador de una identidad cerrada, única, Girondo se presenta ante el lector como un yo fragmentado, penetrado por la alteridad, recorrido por las voces de los otros, cuya personalidad está conformada por un mosaico de lecturas, de vidas ajenas, de retazos de experiencias propias. Un yo múltiple que se hace y rehace constantemente, al contacto y abrigo de los otros, pero, sobre todo, de los textos de los otros. Un yo que construye su autobiografía reescribiendo las biografías ajenas, en un proceso de reensamblaje y transformación de los textos de otros y de los suyos propios:

La autoficción, tal como la concibe Vila-Matas en El mal de Montano, está un paso más allá porque asume que el sujeto de la escritura y/o el de la lectura son un collage de citas, de fragmentos, ecos y resonancias de la desfiguración de otros textos desplazados/despedazados como repeticiones re-escritas que fingen que no fingen ser originales (Ferro 2003: 4).

Si durante toda la lectura de El mal de Montano, tal y como estamos viendo, se observa un deseo explícito por acabar con esa imagen ilusoria del Sujeto moderno como un bloque compacto e indivisible, como totalidad coherente, como esencia inmutable, para apostar por un concepto de identidad abierto, en constante proceso de transformación, y por un yo múltiple que contiene dentro de sí a los otros, es en la segunda parte de la novela, en ese «Diccionario del tímido amor a la vida», donde Girondo nos explica las conexiones entre ese deseo de representar la precariedad del yo y la elección del diario íntimo, propio y ajeno, para reconstruir su biografía:

Me propongo trabajar discretamente en el interior de diarios ajenos y lograr que éstos colaboren en la reconstrucción de mi precaria autobiografía, que naturalmente será fragmentada o no será, se presentará tan fraccionada como mi personalidad, que es plural y ambigua y mestiza y básicamente es una combinación de experiencias (mías y de otros) y de lecturas (Vila-Matas 2007: 107).

Girondo se propone construir su biografía, su personalidad, su identidad, con retazos de la vida de los escritores de diarios que más le han fascinado a lo largo de los años. Y no es casualidad que todos ellos fueran escritores pertenecientes a esa tradición crítica y vanguardista que puso en jaque a la $\mathrm{Mo}$ dernidad normativa en la que se inscribe como continuador el propio Vila-Matas, como no es casualidad que todos ellos expresaran en sus propios diarios ya ciertas dudas acerca de sus respectivas identidades, cierta intuición de la precariedad de sus personalidades, ni que casi todos utilizaran el diario íntimo como género para transgredirlo e insertar en él fabulaciones, narraciones de carácter ficcional, figuraciones de sus propios yoes. Así, los autores escogidos para las entradas de ese diccionario de escritores de diarios (Amiel, Gide, 
Gombrowicz, Kafka, Michaux, Pavese, Pessoa, Renard, Valéry...) respaldan las elecciones que Girondo/Vila-Matas toma para escribir su propio diario. De nuevo Vila-Matas expone su propia propuesta señalando a quienes le precedieron y emprendieron proyectos escriturales similares al suyo, alineándose con una serie de autores que comenzaron en distintos momentos a abrir para la literatura el camino que él mismo se propone seguir explorando.

$\mathrm{Al}$ introducir en su texto, en su diario/diccionario de autores, las biografías de este ejército de disidentes que convoca a sus filas, Vila-Matas asegura que ahora podrá ser «más fiel» a su verdadera personalidad, reconociendo como fundamentales las voces ajenas, las escrituras de otros, en la conformación de su propio yo múltiple y fragmentario. Un yo que contiene por entero a la alteridad y que solo en el reconocimiento y la escucha de esas voces que lo entrecruzan, puede dejar de sentirse un hombre perdido y desarraigado ${ }^{6}$ :

Un diccionario cuyas entradas vendrían dadas por los nombres de los autores de diarios personales que más me han interesado a lo largo de muchos años de lectura de ese género literario tan íntimo; unos nombres de autores que, al reforzar con sus vidas mi autobiografía, me ayudarían a componer un retrato más amplio y curiosamente más fiel de mi verdadera personalidad, hecha en parte a base de los diarios íntimos de los demás, que para eso están, para ayudar a convertir a alguien, que por sí sólo sería más bien un hombre desarraigado de todo, en un personaje complejo y con cierto tímido amor a la vida (Vila-Matas 2007: 106-107).

Lo importante de todo esto, lo vital, es que Girondo, con estos ejercicios de reapropiación, de hurto de las vidas y obras de otros diaristas, que se mezclan con las fabulaciones y fingimientos, con las mentiras y medias verdades sobre su propia biografía que va intercalando en el texto, está concibiendo el diario como un género de ficción más. Esa es la clave: si el género más «íntimo» del yo, el género más personal de ese yo, el más cercano a la «verdadera» identidad del escritor, es considerado y representado como un género de ficción, es porque ese propio yo que pretende reconstruirse a sí mismo a través de una narración de sí, del acontecer de sus días, de sus experiencias y deseos más «propios», es él también una ficción, una figuración ${ }^{7}$.

El único relato posible sobre nosotros mismos ha de ser a la fuerza una ficción, una autoficción, por el mero hecho de ser eso, relato, construcción simbólica e intersubjetiva del yo. Se diluyen los límites entre la realidad y la

${ }^{6}$ Esos escritores, inscritos en la tradición de la Modernidad crítica, constituyen su raíz literaria y vital.

${ }^{7}$ Ocurre igual con la autobiografía, el otro género literario supuestamente fiel a la realidad, a la vida de quien escribe, que es tachado de «sutil ficción»: «Como dice Antonio Tabucchi, "Soares es un personaje de ficción que adopta la sutil ficción literaria de la autobiografía" (...) Como si hubiese buscado disolverse en el tejido de su propia autoficción interminable» (Vila-Matas 2007: 182). 
ficción, se confiere a ambas el mismo estatuto ontológico ${ }^{8}$. Como nos recuerda Girondo citando a Machado, «también la verdad se inventa». Es con la crisis de la Modernidad normativa, con la intuición de cierta parte de los pensadores y escritores modernos de que la Razón, el Sujeto, la Verdad, también eran fábulas, construcciones simbólicas (lingüísticas), cuando empieza ese nuevo camino para la literatura que Girondo prosigue incansable, intentando ir siempre un paso más allá que quienes le precedieron:

La verdad es que ese "nadie dice la verdad" de Renard se iba a convertir en poco tiempo en campo abonado para los diarios ficticios, para la "vida de la mente" de André Gide y poco más tarde para la "construcción de sí mismo" de Gombrowicz y hasta incluso para el proyecto de identidad fragmentada que soy yo, que llevo días sumergido en este diccionario intentando ser lo más veraz posible y dando toda clase de informaciones verdaderas sobre mí mismo, sin lograrlo siempre, porque muchas veces noto que en realidad ya sólo ando buscando, vencido por la verdad imposible, disolverme como un hombre sin atributos en pleno diario (Vila-Matas 2007: 197).

Lo que procura Vila-Matas, a la postre, es demostrar que eso que la crítica ha dado en llamar ahora autoficción, y que muchos se empeñan en percibir como un fenómeno eminentemente contemporáneo, posmoderno incluso, hunde sus raíces en plena Modernidad (en esa Modernidad marginal, crítica, que es la primera en cuestionar y transgredir las normas, valores y certezas del inconsciente burgués dominante en el proyecto moderno ilustrado) y tiene una trayectoria, un recorrido, que no podemos olvidar (apuntaba, como todos los elementos formales, estructurales y semánticos que venimos analizando en este epígrafe, hacia una determinada dirección: señalaba unas carencias, un vacío, una quiebra en la búsqueda de sentido, pero no dudaba de la necesidad misma de esa búsqueda, en contra de lo que ocurre con ciertos usos «posmodernos» de estos elementos narrativos, que a veces se convierten en mera pose superficial).

Pero retrocedamos un poco y ahondemos en el diario como autoficción de ese yo fragmentado, inconcluso, múltiple, mestizo y figurado que es Girondo. La primera parte de la novela se nos presenta como el diario de un crítico literario cuyo hijo, de nombre Montano, está «enfermo de literatura». Ese diario que el narrador-protagonista escribe se va convirtiendo en novela a medida que Girondo narra sus peripecias contra los enemigos de lo literario y profundiza en su deseo de encarnar la literatura, convirtiéndose en un Don Quijote contemporáneo, de la mano de su fiel escudero Tongoy. Tales peripecias, que el lector acepta como posibles, como verosímiles, serán desmontadas en la segun-

\footnotetext{
8 «La conciencia de que la realidad no puede ir más allá de los límites de su representación posibilita que se asimile el estatuto ontológico de la realidad con el de la fícción» (Roca Sierra 2005: 335).
} 
da parte del libro, desmentidas una a una y presentadas como ficción, como figuración. Girondo, en esa segunda parte de El mal de Montano, titulada «Diccionario del tímido amor a la vida», confiesa al lector que su nouvelle de la primera parte mezclaba ficción y realidad, y que mentía respecto a algunos datos biográficos del personaje que habíamos dado por «verdaderos». Nos cuenta, también, que se ha propuesto elaborar un diario en forma de diccionario de autores y contar la «verdad», toda la «verdad» sobre sí mismo. Así, Girondo empieza escribiendo un supuesto diario que se le convierte en novela a medida que lo está escribiendo y que, después, en la segunda parte del texto, se revela como falso diario, como autoficción. En esa segunda parte, Girondo utiliza la estructura del diccionario de escritores, con entradas de sus autores predilectos de diarios íntimos, para ir introduciendo pinceladas de lo que se supone su «auténtica» vida, con el propósito de contarnos, dice, toda la «verdad» sobre sí mismo (así, asegura que no es un crítico sino un escritor con cierta fama, que no tiene ningún hijo y, por tanto, que Montano es una ficción; habla de su madre muerta, confiesa que no fue a Valparaíso a finales de año solo, sino con su mujer, Rosa; aclara la identidad del verdadero Felipe Tongoy...).

Y, aunque se supone que en esta segunda parte nos acercamos más a Girondo, conforme este se va desprendiendo de las máscaras, más claro parece que lo único que hay debajo son nuevas máscaras. Se acrecienta la sospecha, el recelo con respecto a la voz narrativa; una vez activado el mecanismo de la suspicacia en el lector al confesarnos las «mentiras» de la primera parte, Girondo ha conseguido que dudemos de todo lo que cuenta, que pensemos que, de creerlo, estaremos volviendo a caer en su «trampa». Se superponen capas de ficción, el baile de máscaras continúa, y de fondo, resuena lo que sabemos del autor real, el plano extraliterario, la biografía de Vila-Matas, las coincidencias con su personaje Girondo. El propio Girondo nos aclara que la primera parte del libro es autoficcional, ha inventado él una vida que no es real, verdadera, y va a contarnos ahora la verdad, a escribir su «auténtica» biografía, a fuerza de coser a su propio yo diminutos y quebrados fogonazos de las biografías y escrituras ajenas de los autores que incluye en su diccionario: «Empecé a convertir en novela mi diario siendo el narrador que soy pero haciéndome pasar por crítico literario, me fui después construyendo una biografía impostada a base de inyectarme fragmentos de las vidas o de las obras de mis diaristas favoritos» (Vila-Matas 2007: 239).

En la tercera parte de la novela, titulada «Teoría de Budapest» y presentada como una conferencia sobre el diario como forma narrativa, Girondo se dedica a seguir diseccionando la primera parte y añade ahora un desmontaje de la segunda parte, que vuelve a presentarse como una figuración del yo, como una fabulación, como una ficción sobre sí. Volvemos a saber lo que esta vez ya intuíamos: que mucho de lo que Girondo narraba en la segunda parte del 
libro, asegurando estar contando «la verdad» sobre sí mismo, era completamente «falso»:

\begin{abstract}
En cuanto llegue a Monsieur Teste y Paul Valéry, que son las dos últimas entradas previstas para este diccionario de escritores de diarios íntimos, me adentraré en un espacio más fronterizo entre la ficción y la realidad, será posiblemente algo así como un desahogo después de haber sido tan fiel a lo verídico, de haber contado $[\ldots]$ verdades sobre mi fragmentada vida, verdades muy verdaderas y narradas como si no supiera que, como decía Antonio Machado, también la verdad se inventa (Vila-Matas 2007: 146).
\end{abstract}

Así, en la tercera parte de la novela, de la que en la segunda parte se nos había advertido que sería una mezcla de realidad y ficción, se revela que la segunda, en la que Girondo aseguraba estar usando un registro autobiográfico, haber abandonado la autoficción para contarnos «verdades muy verdaderas», era solo una figuración más, una impostación, un fingimiento (aunque ya nos advertía Girondo, en el mismo párrafo en que aseguraba estar siendo fiel a la «verdad», que para hacerlo tenía que actuar deliberadamente como si ignorase que «también la verdad se inventa», poniéndonos sobre la pista de que ese supuesto arrebato de sinceridad podía ser también, como lo habían sido tantas otras cosas en la narración hasta el momento, fingido). Todo esto parece un galimatías, pero es que, efectivamente, la estructura especular, de «mise en abyme», de la narración, pretende, entre otras cosas, al doblarse y redoblarse sobre sí, conformar una madeja revuelta, difícil de desenmarañar para el lector y para el crítico.

En esa tercera parte, en la que se supone que se reflexiona, con el formato de la conferencia, sobre el diario como forma narrativa (lo cual ofrece pistas sobre la intención de Girondo al escribir la primera parte del libro, que no es otra que convertir en género narrativo, ficcional, el diario, y al escribir la segunda, ese diccionario de autores de diarios que transgredieron casi todos ellos el género para ir más allá, o que convirtieron el género en un híbrido donde poesía, reflexión, narración, todo tenía cabida), Girondo se propone, según explica a la audiencia de su conferencia, elaborar en «tiempo real y en directo la construcción en público del diario personal de un escritor que tiene hambre y que se complace en dictar su conferencia al borde del abismo» (Vila-Matas 2007: 208).

La conferencia comienza con la confesión de Girondo de haberse preparado para ella, elaborándose un personaje previamente, para presentarse ante los ojos del público como tal ${ }^{9}$. Se trata de una conferencia sobre el diario como género mestizo, como género de ficción, en la que Girondo no habla sino de su propio diario, de ese que compuso con forma de diccionario de escritores y

\footnotetext{
9 «Me he negado a ducharme y comer, he vivido como un pordiosero y sin probar apenas bocado en una pensión de mala muerte de Buda» (Vila-Matas 2007: 207).
} 
cuya redacción hubo de interrumpir, dice, para asistir a la conferencia. Cuenta cómo Rosa y Tongoy están sentados en la primera fila, y habla largo rato de ellos, en lo que se suponen datos biográficos, para algo después decirnos que ni Rosa ni Tongoy están presentes en realidad: «Deben ustedes estar pensando que ya es hora de que les diga que ni Rosa ni el monsieur existen, pues no hay nadie en la primera fila [...] Está bien, señoras y señores, distinguido público húngaro, voy a dar un golpe de timón, un viraje de vampiro. Diré verdades después de haberles ligeramente mentido» (Vila-Matas 2007: 219). Y pasa a contarnos cómo ha estructurado y concebido la conferencia ${ }^{10}$ y por qué: «Inventé la condición vagabunda de estos tres personajes siguiendo las instrucciones del monsieur, cuyo diseño de la conferencia exigía una parte ficcional — no muy propia de las convenciones de las conferencias - que pudiera ser mezclada, bajo el signo del teatro, con la parte ensayística» (Vila-Matas 2007: 221). Confiesa que está intentando hacer de esa conferencia un microcosmos de lo que escribe en Barcelona, «que reuniera ensayo, memoria personal, diario, libro de viajes y ficción narrativa. Y que repitiera incluso la estructura de mi manuscrito barcelonés, pasando de la ficción a la realidad, pero sin olvidar nunca que la literatura es invención» (Vila-Matas 2007: 222).

Ahí está ofreciendo las claves de sentido de toda la novela y una advertencia clara al lector: el yo literario siempre es un yo figurado, inventado. Los elementos de la «realidad» que se inscriben en el texto literario (en realidad, en el enunciado mismo, en el discurso mismo, sea del tipo que sea) siempre sufren un proceso de ficcionalización. Buscar la realidad en la literatura es un insulto a la propia literatura, que constituye una realidad autónoma en sí misma. La conferencia prosigue explicando algunos de los engaños, de las ficcionalizaciones a las que Girondo ha sometido su vida «real» para inscribirla en el texto y de las propias figuraciones de su yo que han tenido lugar en el transcurso de la conferencia, mientras se nos antoja como lectores que, cuanto más nos aclara Girondo sus engaños, más cerca de la ficción está su relato y se enmascara su verdadero rostro.

La cuarta y última parte de El mal de Montano, desarrollada en forma de diario y titulada «Diario de un hombre engañado», comienza con la entrada del 25 de septiembre, y con la narración de Girondo de cómo terminó su conferencia en Nantes meses atrás. El diario da un giro, se pasa a la segunda persona y comienzan a narrarse una serie de viajes, de huidas, a Valparaíso, a Bu-

${ }^{10}$ Conferencia que es concebida por Girondo, al igual que el diario, como un género mestizo, híbrido, recorrido también por la ficción: «Ya hemos empezado a bordear el tema del diario personal como forma narrativa, ya hemos comenzado a demostrar cómo una conferencia puede ser solemne o simplemente solemnemente libre, pues en ella convive cierta forma narrativa, el vuelo reflexivo del ensayo y una voz autobiográfica, entre otros registros» (Vila-Matas 2007: 211). 
dapest, a Barcelona, de encuentros imposibles con Musil, con Walser... La figuración del yo explora nuevos caminos, adopta nuevas máscaras.

Todos estos juegos de máscaras que se van superponiendo unas a otras, intercambiando, no hacen más que reforzar lo que Girondo a la postre pretende: confundirse él mismo con la ficción, con las distintas personalidades que inventa para sí, con las dispares biografías que ensaya para sí, con los personajes en los que se convierte él mismo y con las personalidades e identidades de todos los escritores de diarios que se insertan en el texto, para librarse de una vez por todas de sí mismo o, mejor, para demostrarse a sí y demostrarnos a todos, que la identidad es a la fuerza múltiple y fragmentaria, que cada uno de nosotros nos desconocemos, que mutamos constantemente, que es imposible saber lo que somos, que a menudo lo que sabemos con certeza de nosotros mismos es que somos unos auténticos desconocidos: «En la era del pacto autobiográfico, en una época en la que predomina la novela del yo, un señor llamado Teste, levantado antes de la aurora, en pijama, con los hombros cubiertos por un chal, anota: Es lo que llevo en mi de desconocido lo que me hace yo» (Vila-Matas 2007: 201). A la postre, solo podemos vislumbrar aquello «en lo que nos estamos convirtiendo» y nunca lo que somos (algo que ya supieron ver en su día los diaristas que Girondo inscribe en su propio texto):

\begin{abstract}
Al igual que otros diaristas, no escribo para saber quién soy, sino para saber en qué me estoy transformando. [...] No es pues la revelación de alguna verdad lo que mi diario anda buscando, sino la descripción cruda, clínica, de una mutación. Empecé mi diario siendo un narrador que añoraba ser un crítico literario, me fui después construyendo una personalidad de diarista gracias a algunos de mis diaristas favoritos, y ahora me veo transformado en un hambriento por voluntad propia: un vagabundo de fondo, al que veo alejarse, dominado por su inquietud, o mejor dicho, por una inquietud que no tiene por qué ser necesariamente suya, pero de la cual participa en cierto modo (Vila-Matas 2007: 213).
\end{abstract}

Al fin y al cabo, ¿qué es la realidad y qué la separa de la ficción? ¿Qué es el yo y cómo podemos estar seguros de la frontera que lo separa del Otro, de que no sea él mismo un Otro, unos Otros? ¿Qué es lo mío, lo propio, lo personal, y qué lo ajeno? ¿No somos extranjeros para nosotros mismos, no tenemos a veces la impresión de que una palabra de otro, una mirada, un gesto, nos pertenecen más que algunas palabras, miradas y gestos propios que ni siquiera reconocemos ante el espejo? ¿No hay acaso inquietudes, deseos, reflexiones de los Otros que sentimos alojadas en lo más profundo de nuestro ser? ¿No es leer un texto siempre apropiarse de la palabra ajena? ¿No somos muchos al mismo tiempo? ¿No somos siempre nosotros, pero también los otros?

La identidad no es fija, estable, sino algo informe en un constante proceso de mutación, que se transforma al contacto con la palabra ajena, con la mirada de los otros. Y lo que Girondo trata al fin de hacernos ver es que escribir un 
diario no consiste en ofrecer un testimonio de nuestro yo completo y cerrado, sino en dar cuenta de esas transformaciones: "Quienes escribieron grandes diarios íntimos en el siglo pasado no lo hicieron para saber quiénes eran ellos, sino que los llevaron a cabo para saber en qué se estaban transformando» (Vila-Matas 2007: 144).

Este artículo, en conclusión, defiende que la narrativa vilamatiana está enraizada en una tradición plenamente moderna, aunque disidente de lo que podríamos llamar la Modernidad normativa, un contradiscurso que a comienzos del siglo XX apunta ya muchos de los rasgos que serán determinantes en la configuración de lo posmoderno, conservando el impulso ético y estético propio de la Modernidad, sin caer en el relativismo absoluto posmoderno.

\section{BIBLIOGRAFÍA CITADA}

Barthes, Roland (1986), «Intertextualidad», en Angelo Marchese y Joaquín Forradellas, Diccionario de retórica, crítica y terminología literaria. Barcelona: Ariel, pp. 217-218.

Ferro, Roberto (2003). «El Mal de Montano de Enrique Vila-Matas: ¿Homenaje a Emilio Renzi?», Revista Hispanista. 18 (julio-septiembre). Accesible en: http://www.hispanista. com.br/revista/artigo157.htm.

Hernández Silvestre, Manuel (2011). «Dialogismo y alteridad en Bajtín», Contribuciones desde Coatepec. 21, julio-diciembre, pp. 11-32.

Kristeva, Julia (1978). Semiótica I. Madrid: Fundamentos.

Mora, Vicente Luis (2012), «Autonovela, metaficción y circularidades», en Marta Álvarez, Antonio Gil González y Marco Kunz (eds.), Metanarrativas hispánicas. Berlín: Lit Verlag, pp. 43-51.

Otxoa, Julia (2007), «Juego y laberinto en la obra de Enrique Vila-Matas», en Irene Andrés-Suárez y Ana Casas, Enrique Vila-Matas. Grand Séminaire de Neuchâtel. Coloquio Internacional Enrique Vila-Matas. Madrid: Cuadernos de Narrativa, Arco Libros.

Pozuelo Yvancos, José María (2007), «Vila-Matas en su red literaria», en Irene Andrés-Suárez y Ana Casas, Enrique Vila-Matas. Grand Séminaire de Neuchâtel. Coloquio Internacional Enrique Vila-Matas. Madrid: Cuadernos de Narrativa, Arco Libros.

Pozuelo Yvancos, José María (2010). Figuraciones del yo en la narrativa. Valladolid: Universidad de Valladolid.

Pozuelo Yvancos, José María (2012), «La tetralogía del escritor de Enrique Vila-Matas», en Felipe Ríos Baeza (ed.), Enrique Vila-Matas, los espejos de la ficción. México: Ediciones Eón.

Ríos Baeza, Felipe (ed.) (2012). Enrique Vila-Matas, los espejos de la ficción. México: Ediciones Eón.

Roca Sierra, Marcos (2005). «La subjetividad narrativa posmodema: procesos determinantes», Revista de literatura. LXVII, 134, pp. 333-348. https://doi.org/10.3989/revliteratura. 2005.v67.i134.98

Ródenas de Moya, Domingo (2007). «La novela póstuma o el mal de Vila-Matas», en Margarita Heredia, Vila-Matas portátil, un escritor ante la crítica. Barcelona: Candaya.

Sánchez-Mesa Martínez, Domingo (1999). Literatura y cultura de la responsabilidad. El pensamiento dialógico de Mijail Bajtín. Granada: Comares. 
Vázquez Medel, Manuel Ángel (2005). La urdimbre y la trama. Estudios sobre el arte de narrar. Sevilla: Alfar.

Vila-Matas, Enrique (2007). El mal de Montano. Barcelona: Anagrama.

Vila-Matas, Enrique (2010). Perder teorías. Barcelona: Seix Barral.

Fecha de recepción: 18 de agosto de 2015.

Fecha de aceptación: 19 de julio de 2016. 